\title{
Amerikanlaşmanın Kültürel Boyutu: Diyarbakır Örneği
}

\author{
Cultural Dimension of Americanization: The Case of Diyarbakır
}

\author{
Yilmaz DEMIRHAN* \\ Ömer TAYLAN**
}

\section{Öz}

Küreselleşme; bazı yazarlara göre, dünyanın mozaiğini tahrip etme, bazılarına göre ise tahkim etme özelliğine sahiptir. Bu yazarlar kendi düşüncelerine meşruluk kazandırmak için sistematik bir paradigma ekseninde argümanlarını ileri sürmüşler. Böylelikle küreselleşme üzerine bilimsel araştırma ve çalışmalarda farklı kuramlar/yaklaşımlar ortaya çıkmıştır.

Genel bir bakış açısıyla küreselleşme kuramları, üç temel başlık altında ele alınmaktadır. Bunlar ekonomik, siyasal ve kültürel kuramlardır. Ekonomik kuramlar, neoliberal ekonomik pazarı kutsayan yaklaşım ile bu pazara eleştirel yaklaşan ve Marxçı bir bakış açısını yansıtan kuram olarak ikiye ayrılır. Siyasal kuram da ikiye ayrılmaktadır. Bir tarafta liberal yaklaşım, diğer tarafta bu yaklaşıma karşı olan anti-liberal kuram yer alır. Kültür kuramlarını ise üç yaklaşım şeklinde tasnif edilebiliriz. Birincisi; kültürel farklılıktır. Bu kurama göre, küreselleşme, sadece yüzeyde meydana gelir ve kültürlerin derin yapıları ondan etkilenmez. Böylelikle kültürler, sadece küreselleşmeye değil, aynı zamanda başka kültürlerin etkilerine de büyük ölçüde kapalı olarak varlıklarını sürdürürler. Kısaca onlar her zamanki gibi olmayı sürdürürler. İkincisi; kültürel karışımdır. Başka bir ifadeyle küresel ve yerelin, yerel ve küresel kültüre indirgenemeyen bütünleşmesinden ortaya çıkan kültürlerin karışımını vurgular. Üçüncüsü; kültürel aynılıktır. Bu kuram küreselleşmenin, dünya genelinde artan aynılığa neden olduğu fikrine dayanır. Bu bakış açısıyla hareket edenler, kültür emperyalizmi, küresel kapitalizm, Batılılaşma, Amerikanlaşma, McDonaldslaşma ve dünya kültürü gibi oluşumlar üzerine odaklanırlar.

Çalışma, üç kuram (ekonomik, siyasal ve kültürel) içerisinden kültürel kurama dayanmaktadır. Kültürel kuramın da bir alt başlığı ve yaklaşımı olan kültürel aynılık, çalışmanın temel odağını ve kritiğini oluşturmaktadır. Çünkü çalışmada kültürel aynılık referans alınarak Amerikanlaşma olgusu ortaya konmaktadır.

Söz konusu Amerikanlaşmanın Diyarbakır özelinde meydana getirdiği etkilerin neler olduğu nitel araştırma yöntemi kullanılarak belirtilmektedir. Metodoloji olarak nitel araştırma yöntemlerinden yarı yapılandırılmış görüşme tekniği esas alınmıştır. Örneklem büyüklüğü 10 kişi olarak belirlenmiştir. Araştırma modeli olarak ise fenomenolojik çözümlemeye dayanmaktadır. Yapılan çalışmanın sonucunda batı ve tüketim kültürünün bireylere nasıl aktarıldığına ve bu kültürü benimseyen kişilerin nasıl davrandıklarına ana hatlarıyla yer verilmektedir. Dolayısıyla kültür bağlamında yumuşak gücün varlığı önem kazandığı görülmektedir.

* Doç. Dr., Dicle Üniversitesi, İİBF, Siyaset Bilimi ve Kamu Yönetimi Bölümü, yilmaz.demirhan@dicle.edu.tr

** Arş. Gör., Dicle Üniversitesi, İIBF, Siyaset Bilimi ve Kamu Yönetimi Bölümü, omer.taylan@dicle.edu.tr 
Çalışmada elde edilen bulgular doğrultusunda Amerikanlaşma, süreç içerisinde kültürel farklılıkları ortadan kaldırmakta, tek-biçimli ve hegemonik özelliği olan Amerikan kültürünü inşa etmektedir. $\mathrm{Bu}$ inșa etme fonksiyonu tüketim kültürünü, toplumsal bir formasyon haline getirmektedir. $\mathrm{Bu}$ formasyon sürecinde bireyler, türdeş nitelikler gösteren kimlikler edinerek kendilerini ifade ve ispat ettiklerine inanırlar. Böylelikle ortada etkin olarak rol oynayan aygıtın batı ve tüketim kültürü olduğu gözlenmektedir.

Anahtar Kelimeler: Amerikanlaşma, Kültür, Tüketim Kültürü, Nitel Araştırma.

\begin{abstract}
Globalization; according to some writers, has the property of destroying the world's mosaic and, in some cases, of arbitrating it. These authors have put forward their arguments in the context of a systematic paradigm in order to legitimize their own thinking. Thus, different theories / approaches emerged in scientific research and studies on globalization.

From a general point of view, theories of globalization are considered under three main headings. These are economic, political and cultural theories. The economic theories are divided into a critique of the approach to the neoliberal economic market and a theory that reflects Marxian point of view. Political theory is also divided into two. There is a liberal approach on the one hand, and anti-liberal theory on the other that opposes this approach. Cultural theories can be classified into three approaches. First; Cultural difference. According to this scheme, globalization only occurs on the surface, and deep structures of the cultures are not affected by it. Cultures thus continue to not only be largely closed to globalization, but also to the effects of other cultures. In short, they continue to be like always. Second; Cultural mixture. In other words, it emphasizes the mixture of cultures emerging from the indivisible unification of global and local, local and global cultures. Third; Cultural sameness. This theory is based on the idea that globalization is causing increased sameness across the globe. The actors follow this point of view focus on forms such as Cultural Imperialism, Global Capitalism, Westernization, Americanization, McDonaldization and World Culture.

The study is based on cultural theory within three theories (economic, political and cultural). Cultural sameness, which is also a sub-title and approach to cultural theory, constitutes the basic focus and critique of the study. Because, in the study, the case of Americanization is put forward with reference to cultural sameness.

It is stated what effects that the Americanization brings to Diyarbakir in particular by using the qualitative research method. Semi-structured interview technique is used as methodology. The sample size is set at 10 people. The research model is based on phenomenological analysis. At the conclusion of the work done, it is outlined how the western and consumer cults are transferred to the individuals, how the individuals do what they do to make them cultural, and how they behave. Therefore, the presence of soft power seems to be important in the context of culture.

Americanization in the direction of the findings of the study, in the process, removes the cultural differences and builds, one-form and hegemonic American culture. This building function makes the consumption culture a social formation. In this formation process, individuals believe that they have expressed and proved themselves by acquiring identities of the same genre. Thus, it is observed that the device that plays an active role is the western and consumer culture.
\end{abstract}

Keywords: Americanization, Culture, Consuming Culture, Qualitative Research 


\section{Giriş}

Holistik bir yaklaşımla küreselleşme döneminden önce, insanların güçlü ve kültürel sürekliliği olan bağları vardı. Bu bağlar insanların ait olduğu cemaatin kültürel kodlarını ve kimliğini kuruyordu. Bu kimlik ve kültür en basitinden, varoluşsal bir mirası, uzun geleneksel yerleşikliğin bir kazanımı, geçmişin bir sürekliliği olarak edindiği bir şeydi. O zaman kimlik ve kültür, yerel toplulukların bir çeşit kolektif hazinesiydi denilebilir. Fakat bunun kırılgan bir şey olduğu ve kaybolabileceği keşfedildi. Bu pek çeşitli kültürel kimlikler dünyasına küreselleşmenin aşındırıcı gücü 1980'lerin ortalarında girmeye başladı. Dolayısıyla küreselleşme; yerelin yerleşikliğini ortadan kaldırdığı, kültürel deneyimi piyasa gerekleriyle damgalayıp tek tipleştirdiği, dünyanın farklılıklarla dolu kültürlerini (Tomlinson, 2014, s. 320) yok ettiği söylenebilir. Üstelik küreselleşme bu realiteye evrensel bir slogan da üretti: Küreselleşmiş bir dünyada yerel kalmak, kültürel anlamda geriliğin göstergesidir (Bayar Bravo, 2010, s. 6).

Küreselleşme olgusunun bu fonksiyonu, bazı yazarlara göre, dünyanın mozaiğini tahrip etme özelliğine sahipken, bazılarına göre ise tahkim etme hüviyetine haizdir. Yazarlar kendi düşüncelerine meşruluk kazandırmak için sistematik bir paradigma ekseninde argümanlarını ileri sürmüşler. Böylelikle küreselleşme üzerine bilimsel araştırma ve çalışmalarda farklı kuramlar/yaklaşımlar ortaya çıkmıştır.

Küreselleşme kuramları üç temel başlık altında sınıflandırılabilir:

- Ekonomik kuramlar: neoliberal ekonomik pazarı kutsayan yaklaşım ile bu pazara eleştirel yaklaşan ve Marxçı bir bakış açısını yansıtan kuram olarak ikiye ayrılır.

- Siyasal kuramlar: bir tarafta liberal yaklaşım, diğer tarafta bu görüşe karşı olan kuram yer alır.

- Kültür kuramlarını ise üç yaklaşıma ayırabiliriz: Birincisi, kültürel farklılıkçılıktır. Bu kurama göre, küreselleşme, sadece yüzeyde meydana gelir ve kültürlerin derin yapıları ondan etkilenmez. Böylelikle kültürler, başka kültürlerin etkilerine de büyük ölçüde kapalı olarak varlıklarını sürdürürler. Bu paradigmanın en ünlü ve tartışmalı örneği Samuel Huntington’un "Clash of Civilizations and Remaking of World Order" (Medeniyetlerin Çatışması ve Dünya Düzeninin Yeniden Yapılması)dır (1993, s. 22-49) ${ }^{1}$.

- İkincisi, küresel ve yerelin bütünleşmesinden ortaya çıkan kültürlerin karışımını vurgular. Üçüncüsü, küreselleşmenin, dünya genelinde artan aynılığa neden olduğu şeklindeki fikre dayanır. Bu bakış açısıyla hareket edenler, kültür emperyalizmi, küresel kapitalizm, Batılılaşma, Amerikanlaşma, McDonaldlaşma ve dünya kültürü gibi oluşumlar üzerine odaklanırlar (Ritzer, 2008, s. 447-451). Çalışmanın kuramsal boyutu, bu yaklaşıma dayanmaktadır. Bu yaklaşımın temel felsefesi aynı zamanda araştırmanın konusunu oluşturmaktadır: Küreselleşme ile birlikte artan bir teknolojik kullanımın ve refahın varlığı, süreç içerisinde kültürel farklılıkları yok ederek, tek-biçimli ve hegemonik özelliği olan Amerikan kültürünü inşa ediyor. Bu inşa etme diğer ismiyle tüketim kültürünü, toplumsal bir formasyon haline getirmektedir. Bu formasyon

1 Huntington, bu makalesinde Soğuk Savaşın sona ermesinden sonra, dünyanın yeniden biçimlenişini politikekonomik bir temele değil, kültürel farklılıklara göre belirleneceğini ifade eder. 
sürecinde bireyler, türdeş nitelikler gösteren kimlikler edinerek ${ }^{2}$ kendilerini ifade ve ispat ettiklerine inanırlar. Metodoloji olarak nitel araştırma yöntemlerinden yarı yapılandırılmış görüşme tekniği esas alınmıştır. Örneklem büyüklüğü 10 kişi olarak belirlenmiştir. Araştırma modeli olarak ise fenomenolojik çözümleme temel alınmıştır.

\section{Küreselleşme: "Dünyanın Amerikanlaşması” veya “Batılılaşması”}

Küreselleşme, Batıdaki gelişmelere yüklenen üstünlük ve dünyanın geri kalanının giderek daha fazla Batıya benzemesi anlamındadır (Ritzer, 2008, s. 441). Bu sebeple "Dünyanın Batılılaşması" veya "Amerikanlaşması", "küreselleşme” olarak nitelendirdiğimiz olgunun bir parçası ve paketidir. Bu bağlamda küreselleşmenin geniş anlamı dünyanın küresel köy haline gelmesidir (Mazrui, 2009, s. 431). Böylelikle global bir sistem içerisinde dünya toplumlarının bir araya geldiği söylenebilir (Şaylan, 2003, s. 71; Modelski, 2009, s. 155). Buna dayanarak küreselleşmenin her şeyden önce bir ideoloji olduğunu söylemekte bir beis yoktur. Çünkü küreselleşme bir bütün olarak ekonomiyi, siyaseti, kültürü ve yaşam tarzlarını etkilediği ve onlara hâkim olduğu aşikârdır. Nitekim küreselleşme gücünü bu totalizasyona ve bunun sonucu olarak polarizasyona borçludur (Arslan, 2004, s. 165). Bu sebeple küreselleşme, hiyerarşiye ve eşitsizliğe yol açmaktadır. Başka bir ifadeyle küresel tabakalaşma (Held vd., 2009, s. 150) ortaya çıkmaktadır Nitekim Batı’nın bu üstünlügü sadece felsefi ve bilimsel boyutla sınırlı kalmadı. Aynı zamanda sosyolojik ve nesnel bir gerçeklik de kazandı. Böylelikle küreselleşmenin vermek istediği bir mesajın var olduğu fark edildi. Mesaj açık olduğu kadar korkutucudur da: "Ben (küreselleşme), her şeyi kontrol edebileceğim bir geleceğe gebeyim".

Küreselleşmenin en görünür alanlarından biri de kültürdür (İçli, 2001, s. 163). Kültür, küreselleşme ile ilintili olarak tartışıldığı zaman, sıklıkla, Amerikan popüler kültürüne gönderme yapılır (Berger, 2003, s. 15; Lieber ve Weisberg, 2009, s. 355). İngilizcenin dünya dili haline gelmesi (Kalb\& Land, 2009, s. 271-273), ister McDonald's ister Starbucks olsun başlı başına küresel bir simge olarak her yeri kaplaması (Hunter\&Yates, 2003, s. 328), küresel internet sisteminin merkezi Amerika Birleşik Devletleri’nde bulunması (Mazrui, 2009, s. 418) bu popüler kültürün örnekleridir.

Popüler kültür, yerel kültüre nüfuz ederek, küresel homojenleşemeye neden olmaktadır (İçli, 2001, s. 163; Bayar Bravo, 2010, s. 12). Homojenlik doğrultusundaki süreç, sıklıkla hegemonya kurma sonucunu ortaya çıkarmaktadır (Ritzer, 2008, s. 442). Çünkü Amerikan ürünlerinin ve düşüncelerinin hâkim olduğu küresel popüler kültür ${ }^{3}$, diğer kültürel üretimlerin çeşitliliğini

2 Batı kültürü, tüm dünyada ortak niteliklere sahiptir. Bu yüzden bu kültürden etkilenen her insanın kültürel yapısı aynılaşmaktadır. Ancak, çoğu zaman, insanlar bu türdeşliğin bir farklılık olduğu kanısındadır.

3 Konu semantik boyutuyla incelendiğinde Anthony D. Smith global-küresel kültür kavramını sorunlu bulmaktadır. Çünkü "kültür" kavramı farklı yaşam biçimlerini ihtiva etmektedir. Fakat global kültür ise tekil bir kültürel duruma işaret etmektedir. Nitekim Amerikan popüler kültürü de kendini global-küresel olarak tescil etmiştir. Smith’e göre kültür(ler), ortak tarihsel olayları geçmişten geleceğe taşıyarak ortak bir kader duygusuna sahiptir(ler). Global kültürün ise doğasında zamansızlık duygusu vardır. Başka bir ifadeyle global kültür tarihsellikten yoksun olduğu için esasen bir hatırasızlıktır. Bu sebeple onu besleyecek ortak bir kader duygusu da yoktur (Smith, 2009). 
yok etmektedir (Lieber\&Weisberg, 2009, s. 356). Nitekim popüler kültür, totaliteryanizme de hizmet etmektedir denilebilir (Çapcıoğlu, 2008). Bu bağlamda Roy Weatherford, Amerika'nın askeri, ekonomik ve eğlence alanındaki hâkimiyeti "dünya barışı"nı sağlayacak ve "nihayet tek bir dünya, tek bir hükümet ve tek bir kültür ideali”nin gerçekleşeceğini ifade ediyor. George Monbiot, Weatherford'tan farklı olarak homojenleştirme ile barışın sağlanamayacağını çünkü çoğulculuk olmadan barışın olamayacağını dile getirir (Akt. Bülbül, 2009, s. 13).

Küreselleşmenin hem bir aşaması hem de bir dayanağı kapitalizmdir. Kapitalizm sahip olduğu özellikler yönüyle küreselleşmeyi de kapsamaktadır. Kapitalizm, sözcük olarak belli bir ekonomik düzeni ifade etmektedir. Ancak, bu tanımın içinde, ifade edilmemiş olsa da çok belirgin bir toplumsallık vardır ${ }^{4}$. Yani belli bir toplumsal düzeni ifade etmektedir (Şaylan, 2008, s. 13). Bu nedenle kapitalizm kendini yeniden üretebilmesi için kültürel üretimin yaşamsal bir işleve sahip olması gerekir. İnsanların sözü edilen yaşam biçimini içselleştirmeleri ve ona göre yaşamaları gerekmektedir. Bu belli bir ideolojinin hegemonik konuma gelmesi demektir. Hegemonik ideoloji, kültürel üretim ile sürdürülebilmektedir. Eğitim-öğretim, estetik ve özellikle eğlence kültürel üretimin belli başlı alanlarına örnektir. Althusser’in (2000, s. 34) devletin ideolojik aygıtları arasında saydığı kültür, okul ve haberleşme (televizyon, radyo, basın vb.) ulus içinde istenen ideolojinin topluma aktarımı işlevini gördüğü gibi, küresel alanda da bu rolü belli ölçülerde yerine getirdiklerini söylemek mümkündür. Örneğin sinema çok büyük yığınlar için geçerli bir kültürel üretim alanıdır ${ }^{5}$; milyonlarca insan için sinema eğlenme ve eğlenirken koşullanma süreci işlevi görmektedir. Bu çerçeveden bakıldığında; Holywood sadece Amerika için değil bütün dünya için milyonlarca insanı eğlendiren, ama eğlendirirken hegemonik ideolojiyi yeniden üreten filmler yapmaktadır (Şaylan, 2003, s. 152). Bu nedenle Amerikan müziğinin, modasının, gıdasının, filmlerinin ve mekânlarının yaygın etkisi, sıklıkla "yumuşak güç" olarak adlandırılan şeyin kısmen bir yansımasıdır. Birleşik Devletler hiç kimseyi bu ürünleri kullanması için zorlamaz. Fakat onlar yine de devasal bir çekiciliğe ve tüketici cazibesine sahiptir (Murray, 1995, s. 48; Lieber\&Weisberg, 2009, s. 356). Çekiciliğinin ve cazibeliğinin püf noktası insanlar için baş döndürücü imajlar, tasvirler ve kimlikler ${ }^{6}$ üretmesidir. Bu dünyanın dışında kalanı ya öteki olarak tayin etmekte ya da geri kalmış olarak yaftalamaktadır. Fakat bu işlevini doğrudan veya aşikâr bir şekilde yapmamaktadır. Bireylerin veya toplumun damarlarına şırınga ettiği psikolojik reflekslerle

4 Kapitalizmin toplumu düzenlemeye muktedir olduğuna dair bilgi için bkz. (Weber, 2011).

5 Kültürel üretimin en önemli araçlarından biri de televizyondur. Postman’a göre, televizyon okuma-yazma kültürünü genişletmez ve pekiştirmez. Tersine okuma-yazma kültürüne saldırır ve insanların kendi disiplin alanlarını öğrenip uygulamalarına da izin vermez. Örneğin doktorlarımız, akademisyenlerimiz, avukatlarımız, eğitimcilerimiz ve televizyon habercilerimiz, kendi disiplin alanlarının gerekliliklerini karşılamaktan ziyade iyi bir şovmenliğin gerektirdiği davranışlara kafa yormaktadırlar. Bu yüzden eğer, televizyon herhangi bir şeyin devamıysa on beşinci yüzyıldaki matbaanın değil, on dokuzuncu yüzyıl ortasında fotoğrafın başlattığı geleneğin devamıdır (2006).

6 Çoğu kez yetişkin bireyleri bile etkileyen bu mesajlar/kimlikler, henüz toplumsallaşma ve yetişkin birey olma yolundaki çocuğu daha fazla etkilemektedir. Dolayısıyla çocuk çalışarak elde etmek, başarmak ve erdemli olmak gibi pek çok insani değer yargısının yerine, salt tüketerek mutlu olunacağı yolundaki düşünceye yönlendirilmektedir (Karakaş, 2006, s. 313). Böylece çocuğun imajlar ve kimliklerle olan ilişkisi doğrudan çocuğun değer yargılarını belirlemede önemli bir faktör olmaktadır. 
yerine getirmektedir. Ve adeta Jeremy Bentham'in Panopticon tipi hapishane modelinde ${ }^{7}$ olduğu gibi görünmeden iktidarı/hegemonyayı sürekli hale getirmektedir.

\section{Amerikan Kültür İşletmeleri/Küreselleşmenin Dominant Failleri}

Batı kültürü ve medeniyeti ortalama beş yüzyılda güçlü ve etkili bir hale geldi. (Mazrui, 2009, s. 431). Batı́nın ya da Batı Düşüncesi’nin başarısı, her şeyden önce Batı liberalizmine alternatif olduğu varsayılan sistemlerin tükenmesinde kendisini gösterdi (Fukuyama, 2009, s. 175). Bunun etkisiyle dünya ekonomisi, temel dinamikleri bakımından uluslararasılaşmıştır, kontrol edilemez piyasa güçlerinin hâkimiyeti altına girmiştir ve temel aktörler hiçbir ulus devlete bağlllık hissetmeyen ulus-ötesi şirketlere sahip hale gelmiştir (Hirst ve Thompson, 2009, s. 43). Bundan dolayı küreselleşme, sadece ekonomik faaliyetlerin milli sınırlar ötesinde coğrafi genişlemesini içermez; ayrıca bundan daha önemli olan uluslararası alana yayılmış faaliyetlerin fonksiyonel entegrasyonu da içerir (Dicken, 2009, s. 57). Bu şirketler, mali piyasalara ve diğer ekonomik eğilimlere çok güçlü yönetim baskıları uygulayabilirler (Hirst\&Thompson, 2009, s. 44) ve şartlarda meydana gelen farklılıklara göre üretimi bütün dünya ölçeğinde değiştirebilirler (Perratonvd., 2009, s. 38). Bu yönüyle şirketler küreselleşmenin dominant failleridir (Giddens, 2009, s. 165). Başka bir ifadeyle dünyanın yeni muktedirleri, karar verme ve uygulama pozisyonuna sahiptirler.

$\mathrm{Bu}$ şirketler dünyaya egemen olmak istiyorlar ve nitekim isteklerinde de başarıya ulaşıyorlar (Ritzer, 2009, s. 371). Başarısında etkin olan faktörler ise verimlilik, hesaplanabilirlik, öngörülebilirlik, insanların yerine teknolojiyi geçirme yoluyla denetim ve rasyonelliğin irrasonelliğidir (Ritzer, 2008, s. 451). Örneğin McDonald’s ve Starbucks Coffee işletmeleri, kurulduğu her yerde aynı servis sistemini ve menüyü sunmaktadır. Bu ise küresel düzeyde temel menünün değişmediğini göstermektedir. Bunun kaçınılmaz sonucu ise bir standartlaşmayı ve rasyonelleşmeyi doğurmaktadır. İnsanların bu hayat tarzına adapte olmasıyla geleneksel değerler siliksizleşerek yerini modern hızlılık ve çabukluğa bırakmaktadır. McDonaldlaşma şirketleri pek çok kültürün içine de yerleşmiştir. Dünyada istedikleri yere yerleşen ve kaynak sağlayan Amerikan kültürü, insanların haz duygularını tahrik ederek kendi formatına uygun tüketiciler de meydana getirmektedir.

Murray’n ifadesiyle Amerikan kültürü, seri üretim yöntemiyle kitlesel tüketimi önceden varsaymaktadır (1995, s. 48). Bu sistem içinde, çoğunluk, düşük ücretler için uzun saatler çalışırken, çok az kişi, büyük kazançlar sağlamaktadır (Ritzer, 2008, s. 5). Hâlbuki Jefferson'un ünlü Bağımsızlık Deklarasyonu’nda “Tüm insanlar eşit olarak yaratılmıştır” diye ilan etmektedir. Ancak sonrasında Amerikan ekonomisinin kölelik üzerine kurulduğu görülmektedir (Mazrui, 2009, s. 422). Buradan hareketle Amerikan kültüründe bir çelişki olduğu söylenebilir. Nitekim Amerikan kültürünün temeli olan ekonomik dinamikler birer birer çatlamaktadır. Bu sebeple tarihte yaşanan bütün buhranlardan daha büyük bir buhranın yaşanacağı beklentisi vardır.

7 Jeremy Bentham’ın Panopticon tipi hapishane modeli hakkında detaylı bilgi için bkz. (Foucault, 1992, s. 251-285; Bauman, 2014, s. 42-64). 
Çünkü sarsıntı geçiren sadece ekonomi değil, insanın sahip olduğu tüm değerler de bir travma geçirmektedir. Ve bu travma sürdürülebilir değildir.

\section{Vitrinde Yaşıyoruz: “Görünüyorsam O Halde Varım”}

Rene Descartes (1596-1650) göre, sahiplik düşünceye bağlıdır. Yani özne olmanın şartı "cogito ergo sum"dır yani o, insanoğlunun yaratılışının en önemli esprisini düşünen bir varlık olmaya dayandırır. Ancak Andre Gide (1869-1951), Descartes’e karşı çıkarak sahiplik için sadece var olmak yani şüphe etmek yetmez. Aynı zamanda duyumsamak da gerekir. Başka bir ifadeyle "duyumsuyorum, o halde varım". Varlığın belirtileri bu kez duyu organlarına bağlanmıştır. Albert Camus (1913-1960) ise Başkaldıran İnsan adlı eserinde, varlığı (je me rêvolte, doncnoussommes) "başkaldırmaya” bağlamıştır. Yani "başkaldırıyorum, öyleyse varız" demektedir (Şeriati, 2013, s. 21).

Ancak küreselleşmenin meydana getirdiği atmosfer ile sahipliğin/öznenin semptomları da değişime uğramıştır. Çünkü küreselleşme "üretim sistemleri ve tüketim ilişkileri” temelinde belirlenen yeni bir durumu ortaya çıkarmıştır (Yıldız, 2012, s. 119). Bu yeni durumda varlığın temeli artık, "düşünmek", “duyumsamak" ve "başkaldırmak” değil, tüketmek, harcamak ve görünmek olmuştur (Roscoe, 2015, s. 13). Çünkü bireylerin toplum içindeki prestij ve statüleri; tükettikleri, harcadıkları ve göründükleri nesnelerle ölçülür hale gelmiştir. Dolayısıyla bireylerin zihin dünyaları, parametreleri ve temel dayanakları da büyük ölçüde bir metaformoz geçirmiştir. Önceleri mahremiyete önem veren bireyler, özel alanı bir çırpıda "aleniyet hakkı"na sahip bir alan olarak tanımlanmaya başladılar. Böylelikle birey, ailesinin sunumunu ön plana çıkardı. Özel hayata dair ilişkiler sayıların otoritesine başvurularak savunulur duruma geldi: "Bunu herkes yaşıyor(muş)", "Bunu herkes yapıyor(muş), "Bunu herkes beğeniyor(muş) gibi... Debord, "sahip olma"nın itibarını "miş gibi”lik durumuna dayandırmaktadır (2016, s. 38). "Miş gibi” algısı Lacan'cı düşüncede sahtekârlıktan ibarettir. Sahtekârlık baştan çıkarır çünkü insan yalnızca sahte hakikat düşüncesiyle yaşayabilir. Eğer bir stratejiden söz edilecekse o da "gösteri"nin kendisidir (Yıldız, 2012, s. 125). Gösterinin bu denli toplum yaşamına girmesi, yeni bir yaşam biçimini ortaya çıkarmıştır.

Bu yeni yaşam tarzında birçok şeyin gösterildiği için göründüğü kadarıyla var olduğu, sergilendiği için seyredildiği kadarıyla değer kazandığı bir toplum ortaya çıktı (Gürbilek, 2001, s. 29). Daha çok görünür olan, kendisinden öncekileri devre dışı bırakmaktadır. İşte böyle bir durumda bireyler; kabul edilebilmek, iyi giyindiklerini kanıtlamak, modaya uymak, günümüzün yaygın söylemiyle "trendy yakalamak" için sürekli tüketime yönelmektedirler. Bunun içinde iletişim araçlarını kullanmak, iletişim araçları içeriğinde yer bulmak, 15 saniyeliğine de olsa şöhret olmak temel amaçlar arasında olmaya başlamıştır. Medyada olumlu ya da olumsuz bulunmanın önemi yoktur. Çünkü medyada olmak tüm kaygıların önündedir (Yıldız, 2012, s. 127-129). Örneğin; insanlar bulunduğu ortamda hemen bir selfie ya da bir fotoğraf çekerek sosyal medyada paylaşmaktadırlar. Böylelikle ait oldukları mekân ve kültür onlara bir imaj ve ikon olma şansını sunmaktadır. İnsanların karşılıklı olarak alıp verdikleri artık fikirler değil, imajlardır (Postman, 2016, s. 118). Bu tüketim toplumunun 
yeni bir iletişim biçimidir. İnsanlar şimdiye dek hiç olmadığı kadar kendileriyle meşgul oluyorlar, kendileriyle ilgilenmesini istiyorlar. Dolayısıyla tüketim kültürü sadece harcamak, görünmek eylemi değil, aynı zamanda kendilik saplantısıdır. Çünkü suda yansıyan kendi görüntüsüne hayranlıkla bakan Narkissos mitinin yerini, tablet veya telefonundaki kendi fotoğraflarına bakan bireyler almıştır (Ergün, 2016, s. 68-69). Bu yeni birey modeli, sadece kendini görüntüde var eden, benliğini görünürlük üzerinden yansıtan özellikleri ile önceki dönemlerin birey tipinden ayrılmaktadır. Özetle epeydir vitrinde yaşıyoruz hepimiz (Gürbilek, 2001, s. 29) ama bihaberiz.

Gösterinin sahteliğiyle ortaya bir de atma toplumu çıktı. Bu atma eylemi sadece çöp atmaya ilişkin bir edim değildir. Aynı zamanda değerlerin, hayat tarzlarının, istikrarlı ilişkilerin ve şeylerin atılması anlamına gelmektedir (Harvey, 2009, s. 309). İlişkiler geçici ve anlıktır.

İnsanlar sosyalleşmeyi taparcasına önemsemelerine rağmen a-sosyal kişilikler haline gelmeye başladılar (Yıldız, 2012, s. 128). Bu kişiliklerin meydana gelmesinde Amerikan kültürünün büyük oranda etkisi bulunmaktadır (Bülbül, 2009, s. 24). Bu kültür insanı bireyselliğin dehlizlerine hapsetmekte sosyalliği sanal alanda geçici ve sözelden çok yazı ve görüntü üzerinde yeniden kurgulamaktadir.

Bocock’a göre kimlik duygusu, artık etnik köken veya cinsiyet yoluyla insanlara kazandırılan bir şey olarak düşünülmemelidir. Kimliği kazanma veya oluşturma sürecinde tüketim önemli bir rol oynamaktadır. Bir insan kendiliğinden "cazip bir kadın” veya "yakışıklı bir erkek” olamaz. İnsanlar, Batı kimliğini alarak bu imajı yakalayabilirler. Giysiler, yiyecekler, yemekler ve vakit geçirilecek mekânların hepsi, bu süreçte rol oynayabilecek şeylerdir (2009, s. 74). Böyle bir toplumun önceliği tüketimdir. Bu tüketimin talep ettiği şey ise yeni bir kimlik yani kişiliktir. Bu kişilik, zamanla tüm öz değerlere yabancılaşmaktadır. Dolayısıyla kişi, gerçek yaşamdan da farkında olmadan tecrit olmuş bir pozisyona düşmektedir.

\section{Yöntem}

Yukarıdaki sayfalarda küreselleşmenin kültürel boyutlarının nasıl oluştuğu ve kendini hangi kurumlar üzerinden var ettiği, bu küresel kültürün bireylere nasıl aktarıldığı, bireylerin kendilerini bu kültüre ait hale getirmek için neler yaptıkları, nasıl davrandıklarına ana hatlarıyla yer verildi. Çalışmanın bundan sonraki kısmında Amerikan kültürünün Diyarbakır'daki yansımalarına bir alan araştırması bağlamında bakılacaktır. Bu çerçevede yapılan görüşmelerin verileri aktarılacaktır. Dolayısıyla bu bölümde araştırma deseni, evreni, örneklemi, verilerinin toplanması ve verilerin analizi konularında bilgi verilmiştir.

\section{Araştırma Deseni}

$\mathrm{Bu}$ çalışma, nitel araştırma ${ }^{8}$ yöntemlerinden görüşme tekniğinin yarı-yapılandırılmış mülakat yöntemi ile gerçekleştirilmiştir. Araştırma ile ilgili gerekli ve yeterli veri 10 kişi ile görüşüldükten sonra elde edilmiştir. Dolayısıyla görüşme bu sayıdan (10) sonra durdurulmuştur.

8 Nitel araştırmanın temel özellikleri hakkında detaylı bilgi için bkz. (Yıldırım ve Şimşek, 2013, s. 45-54; Robson, 2015, s. 575-610). 
Çalışmada, küreselleşme etkisiyle katılımcıların davranış kodlarını belirlemek, onları harekete geçiren etkilerin, motivasyonların neler olduğunu saptamak ve bakış açılarını, duygularını, değerlerini, algılarını ortaya koymak hedeflendiği için nitel araştırma desenlerinden durum çalışması ${ }^{9}$ tercih edilmiştir.

\section{Evren ve Örneklem}

Araştırmanın evreni Diyarbakır'da Amerikan kültürünü birebir yansıtan veya yaşatan küresel markaların eğlence yerlerinde vakit geçiren bireyler, evren olarak belirlenmiştir. Dolayısıyla alan araştırmasının yapıldığı Diyarbakır'daki McDonald's ve Starbucks Coffee işletmelerine ait nicel veriler Tablo 1 ve 2'de yer almaktadir.

Tablo I: McDonald's işletmesine ait bazı veriler

\begin{tabular}{|l|c|c|c|}
\hline \multicolumn{4}{|c|}{ McDonald's } \\
\hline & Şube Sayısı & İlk Açıldığı Yer & İlk Açıldığı Tarih \\
\hline Dünya & 32000 & ABD/California & 1940 \\
\hline Türkiye & 260 & İstanbul/ Taksim & 1986 \\
\hline Diyarbakır & 3 & Ninova Park & 2007 \\
\hline
\end{tabular}

Tablo 2: Starbucks Coffee işletmesine ait bazı veriler

\begin{tabular}{|l|c|c|c|}
\hline \multicolumn{4}{|c|}{ Starbucks Coffee } \\
\hline & Şube Sayısı & İlk Açıldığı Yer & İlk Açıldığı Tarih \\
\hline Dünya & 21000 & ABD/Washington & 1971 \\
\hline Türkiye & 344 & İstanbul/ Erenköy & 2003 \\
\hline Diyarbakır & 2 & Ceylan Karavil Park & 2014 \\
\hline
\end{tabular}

Araştırmada olasılıklı olmayan örnekleme yöntemlerinden ${ }^{10}$ biri olan amaçlı örnekleme yöntemi ${ }^{11}$ diğer adıyla ölçüt örnekleme kullanılmıştır. Amaçlı örneklemede öğeler, örnek için çalışma evreninden rastgele değil, belli özelliklerinden dolayı ve/ya araştırmacının kendi kararına göre seçilirler (Böke, 2014, s. 125). Söz konusu katılımcılara yönetilecek sorulara en iyi cevap verebilecek kişiler ve kriterler iradi olarak çalışmacı tarafından belirlenmiştir. Gerekli ve yeterli veri 10 kişi ile görüşüldükten sonra elde edilmiştir. Dolayısıyla görüşme bu sayıdan (10) sonra tamamlanmıştır. Buna göre 10 kişi örneklem büyüklüğü olarak belirlenmiştir. Bu kişilerin birinci kriteri, cinsiyet ve meslek farkı gözetmeksizin TÜİK’in belirlediği standartlara uygun

9 Durum çalışması hakkında detaylı bilgi için bkz. (Yıldırım ve Şimşek, 2013, s. 313-329).

10 Olasılıklı olmayan örnekleme yöntemi hakkında detaylı bilgi için bkz. (Böke, 2014, s. 122-132).

11 Amaçlı örnekleme yöntemi hakkında detaylı bilgi için bkz. (Böke, 2014, s. 125-126). 
olarak orta-üst sınıfa ${ }^{12}$ mensup olmalarıdır. Çünkü böyle bir niteliğe sahip olan insanların batı tarzı mekânlara gitme isteklerinde ekonomik olarak bir kaygı görülme ihtimali düşük olacaktır. Katılımcıların ikinci kritiği ise, yaş aralığının 25-35 olmasıdır. Bu yaş aralığının seçilmesinin başlıca sebebi 25 yaş altının geleneksel mekânlara, 35 yaş üstünün ise modern mekânlara karşı ilgisiz olma ihtimalinin yüksek olabileceği varsayımından kaynaklanmaktadır. Bu yaş aralığının hem geleneksel hem de modern kültürü yaşama ihtimali daha yüksektir. Katılımcıların üçüncü kriteri en az lisans eğitimine sahip olmaları şeklinde belirlenmiştir. Buna göre örneklem kapsamında coğrafi olarak Diyarbakır'da Ceylan Karavil Park AVM'deki Starbucks Coffee ve Ninova Park AVM'deki McDonald's belirlenerek yaşamının büyük bir bölümünü burada geçiren/ tüketen ve yukarıda belirtilen üç kriteri sağlayan (orta-üst sınıf, 25-35 yaş aralığı, en az lisans eğitimi) bireyler seçilmiştir.

Son olarak katılımcıların eğitim, cinsiyet, meslek ve medeni hal gibi demografik özellikleri Tablo 3'de verilmiştir.

Tablo 3: Çalışma Grubunun Demografik Özellikleri

\begin{tabular}{|c|c|c|c|c|}
\hline Katılımcllar & Cinsiyet & Yaş & Ĕgitim & Meslek \\
\hline K1 & Kadın & 35 & Y. Lisans & Genel Sekreter \\
\hline K2 & Kadın & 30 & Lisans & Doktor \\
\hline K3 & Erkek & 32 & Lisans & Doktor \\
\hline K4 & Erkek & 30 & Y. Lisans & Öğretim Elemanı \\
\hline K5 & Kadın & 25 & Lisans & Öğretmen \\
\hline K6 & Erkek & 30 & Y. Lisans & Savc1 \\
\hline K7 & Kadın & 33 & Doktora & Öğretim Üyesi \\
\hline K8 & Kadın & 29 & Lisans & Mühendis \\
\hline K9 & Erkek & 32 & Y. Lisans & Avukat \\
\hline K10 & Erkek & 34 & Y. Lisans & Mühendis \\
\hline
\end{tabular}

Ayrıca bu çalışmada McDonald's ve Starbucks Coffee’nin müdürleri ve çalışanları ile derinlemesine mülakat yaparak onların izlenimlerini ve müşteri profilini nasıl tanımladıklarını analiz etmek amaçlanmıştı. Ancak McDonald's ve Starbucks Coffee’nin müdürleri ve çalışanları kurumsal olarak bilgilerini paylaşamayacaklarını dile getirdiler. Bu sebeple çalışmada bu bilgilere yer verilemedi.

\section{Verilerin Toplanması}

$\mathrm{Bu}$ çalışmada veri toplama tekniklerinden yarı-yapılandırılmış görüşme tekniği kullanılarak aşağıda yer alan sorulara cevap aranmıştır. Bilimsel araştırmalarda görüşmeye dayalı üç yöntem

12 http://www.gazetesabun.com/tuik-verilerine-gore-turkiyenin-gelir-dagilimi/ erişim tarihi 29. 11. 2016. 
bulunmaktadır. Birincisi tamamen yapılandırılmış görüş̧me olup, genellikle önceden oluşturulmuş bir düzende, sabit ifadelerle daha önceden belirlenmiş sorular vardır. Görüşmeye dayalı anket sorularından tek ve önemli farkı, daha fazla sayıda açık uçlu soruların kullanılmasıdır. İkincisi yarı-yapılandırılmış görüşme olup görüşmeci, kapsam ile ilgili başlıkların kontrol listesini, varsayılan ifadeleri ve soruların sırasını sunan bir görüşme rehberine sahiptir. Ancak, genellikle, ifadelerin ve soruların sırası görüşmenin akışına göre şekillenmektedir ve ek olarak görüşülen kişinin söylediklerini devam ettirebilmek için planlanmamış sorular da sorulabilmektedir. Sonuncusu ise yapılandırılmamış görüşme olup, araştırmacı ve katılımcı arasında etkileşim kendiliğinden gelişir ve sorular önceden belirlenmediği için görüşme katılımcının verdiği cevaba göre şekillenir. Bu nedenle araştırmacı her katılımcıdan farklı cevaplar alabilir ve elde etmek istediği veriye ulaşmak için tekrar tekrar görüşmek durumunda kalabilir (Robson, 2015, s. 347354; Gürbüz \& Şahin, 2016, s. 187-190). Araştırmada kullanılan görüşme soruları araştırmacılar tarafından hazırlanmıştır. Çünkü ilgili yazında benzer bir çalışmaya rastlanılmamıştır. Dolayısıyla uygulama açısından literatürde eksiklik vardır. Görüşme formlarına katılımcılar ilgili sorulara cevaplarını sözlü (ses kayıt) olarak bildirmişlerdir. Bu veriler, araştırmacılar tarafından çözümlenerek temalar oluşturulmuştur. Her bir katılımcıya ayrı bir kod verilmiştir. Kodlar araştırmacı tarafından düzenlenmiştir.

Görüşme formunda üç tane soru yer almaktadır. Bu sorular şunlardır:

Soru 1) Amerikan kültürü denince ne anllyorsunuz?

Soru 2) Amerikan kültürüne niçin sahip olmak istersiniz?

Soru 3) Sizce Amerikan kültüründen dolayı bir kimlik veya kültür erozyonu yaşanıyor mu?

\section{Verilerin Analizi}

Yarı yapılandırılmış görüşme yöntemi ile gerçekleştirilen bu alan araştırmasında katılımcılarla 35-40 dakikalık yüz yüze (face to face) görüşmeler yapılmıştır. Görüşmeler elektronik cihazlarla kayıt altına alınmış, daha sonra çözümleri yapılmıştır. Araştırma verileri metne aktarılırken katılımcıların en çok üzerinde durdukları noktalar, temalar şeklinde gruplandırılmıştır. Elde edilen bu verilerin analizinde ise betimsel analiz yaklaşımı ${ }^{13}$ kullanılmıştır.

Betimsel analiz yönteminde veriler görüşülenden elde edildiği şekilde değiştirilmeden alıntılar şeklinde okuyucuya aktarılır. Farklı kişilerin aynı soru hakkındaki farklı düşüncelerinin görüşülenlerden elde edildiği tarzda aktarılması esastır (Demir, 2014, s. 313).

Bununla birlikte özgün görüş ve düşünceleri yansıtacak şekilde doğrudan alıntılara da yer verilmiştir. Veri seti okunarak anlamlı birimler bulunmuş, kodlamalar yapılmış ve geçici temalar oluşturulmuştur. Temalar elde edilen veriler sonucunda oluşturulmuştur. Kavramsal kodlama da görüşülen bireylerden elde edilen verilere dayanılarak yapılmıştır. Veri analizinin son aşamasında

13 Betimsel analiz yaklaşım hakkında detaylı bilgi için bkz. (Yıldırım \& Şimşek, 2013, s. 256-258). 
ise elde edilen bulgular açıklanmış, yorumlar ve sonuçlar sunulmuştur. Araştırma verilerinin sunumunda katılımcılara verilen kodlardan yararlanılmış ve bazı görüşlerden doğrudan alıntılar yapılarak yorumlar desteklenmiştir.

\section{Bulgular}

Elde edilen verilerden yola çıkılarak araştırma bulguları 3 kategoride ele alınmıştır. Bunlar:

1. Amerikan kültürünün anlamsal dünyasının ne(ler) olduğu.

2. Amerikan kültürünü tercih etme nedenlerinin ne(ler) olduğu.

3. Bir kültür ve kimlik erozyonunun yaşandı̆̆ı.

Amerikan kültürünün anlamsal dünyasının neler olduğuna ilişkin bilgiler Tablo 4’te verilmiştir.

Tablo 4: Amerikan Kültürünün Anlamsal Dünyasının Neler Olduğu

\begin{tabular}{|c|c|l|c|}
\hline Soru & Temalar & Cevaplar/Görüşler & Frekans \\
\hline \multirow{2}{*}{$\begin{array}{c}\text { Amerikan } \\
\text { kültürü } \\
\text { denince ne } \\
\text { anlyyorsunuz? }\end{array}$} & Tema 1 & $\begin{array}{l}\text { • Popüler kültür } \\
\bullet \text { Batı kültürü }\end{array}$ & 7 \\
\cline { 2 - 4 } & Tema 2 & $\begin{array}{l}\text { ・ Kapitalist sistem } \\
\bullet \text { Modern toplum }\end{array}$ & $\mathbf{5}$ \\
\hline
\end{tabular}

Amerikan kültürünün katılımcıların zihni dünyalarında nasıl bir yere sahip olduğu ve bunu nasıl isimlendirdikleri 15 kodlama olarak belirlenmiştir. Buna göre Amerikan kültürü, popüler ve Batı kültürü anlamına gelmektedir. Nitekim katılımcıların bu görüş ekseninde yoğunlaştıkları görülmektedir. Amerikan kültürünün anlamsal dünyasının neler olduğu frekans büyüklüğüne göre sırasıyla Tema 1, Tema 2 ve Tema 3 şeklinde sıralanabilir.

Bu kategoriye yönelik öne çıkan görüşlere ilişkin katılımcıların kendi ifadelerinden birkaçı şu şekilde aktarılabilir:

"Belki de Amerikan kültürü denen şey kapitalist sistemdir. Bu sistem ise birçok şeyi düşünmemize izin vermeyecek şekilde hayatı dizayn etmiştir.” (K1)

“Amerikan kültürü namı diğerle Batı kültürüdür.”(K2)

"Her kültür, kendi insanını inşa etmektedir. Ama bir kültür var ki diğer tüm kültürlerden farklıdır. İste bu kültür, Batı kültürüdürr." (K3) 
"Kültürler birer tarihsel hafıza ve kimliktir. Bana da ayı bir "kimlik" lazım. Kimlik ise bir farklilıktır. Bu farklılık ancak dünya çapında "marka” olmuş Batıya ya da Batı kültürüne hastır."(K8)

"Amerikan kültürü değimiz șey, dünyaya egemen olan kültürdür. Bu egemenliğin ekonomik dayană̆ kapitalizmdir." (K9)

Amerikan kültürüne sahip olmanın nedenlerine ilişkin bulgular Tablo 5’te verilmiştir.

Tablo 5: Amerikan Kültürünü Tercih Etme Nedenleri

\begin{tabular}{|c|c|c|c|}
\hline Soru & Temalar & Cevaplar/Görüşler & $\mathrm{f}$ \\
\hline \multirow{3}{*}{$\begin{array}{l}\text { Amerikan kültürü } \\
\text { sizi nasıl ve hangi } \\
\text { argümanlarla } \\
\text { etkilemektedir? }\end{array}$} & Tema 1 & $\begin{array}{l}\text { - Güven sunmakta } \\
\text { • Modernliği sunmakta }\end{array}$ & 3 \\
\hline & Tema 2 & $\begin{array}{l}\text { - Farklı kimlikler, statüler ve prestijler sunmakta } \\
\text { - Sanal bir hayatta yaşama imkânı sunmakta }\end{array}$ & 7 \\
\hline & Tema 3 & $\begin{array}{l}\text { - Kendini kanıtlama imkânı sunmakta } \\
\text { - Var olma șansını vermekte }\end{array}$ & 4 \\
\hline
\end{tabular}

Amerikan kültürüne bireyler niçin sahip olmak istemekte kategorisinde 14 kodlama olduğu görülmektedir. Buna göre katılımcıların Amerikan kültürüne sahip olmanın nedenlerinin başında farklı kimlikler, statüler ve prestijler gelmektedir. Frekans büyüklüğüne göre Tema 2, Tema 3 ve Tema 1 şeklinde sıralanabilir.

Bu kategoride öne çıkan görüşlere ilişkin katılımcıların kendi ifadelerinden birkaçı şu şekilde aktarılabilir:

“Bu kültürün en cazip yönü insanların yaşamlarını birbirine benzettiği için güven sunmaktadır."(K4) "Bizler zamanla modernliğe entegre olduk. Bu ise farklı kimlikler, statüler ve imajlar sağladı" (K5)

"Batı kültürünün birinci özelliği kapsayıcı ve evrensel olmasıdır. Bu sebeple bütün kültürler Batı kültürüne endekslenmektedir. Böylelikle Batı kültürü hiyerarşik olarak üstün hale gelmektedir. Haliyle bu kültürün etki sahasındaysan varsın ve kendini kanıtlamış demektir."(K6)

"Gerçek hayatta belirli fiziksel ve maddi özelliklere sahibiz. Fakat bu kültür sayesinde yani sosyal medya aracılı̆̆ıla kendimizi olduğumuzdan çok farklı gösterebiliriz veya farklı bir kişilik, kimlik meydana getirebiliriz. Nitekim bunu da yapıyoruz."(K7).

Amerikanlaşmanın kültür ve kimlik olarak yol açtığı krizlere ilişkin bulgular Tablo 6’da verilmiştir. 
Tablo 6: Amerikan Kültürünün Sebep Olduğu Kültür ve/ya Kimlik Erozyonu

\begin{tabular}{|c|c|c|c|}
\hline Soru & Temalar & Cevaplar/Görüșler & $\mathrm{f}$ \\
\hline \multirow{5}{*}{$\begin{array}{c}\text { Sizce Amerikan } \\
\text { kültüründen dolayı } \\
\text { bir kimlik veya kültür } \\
\text { erozyonu yaşanıyor mu? }\end{array}$} & Tema 1 & $\begin{array}{l}\text { - Ahlaki ve kültürel boşluk } \\
\text { - Yabancllaşma ve yalnızlaşma }\end{array}$ & 2 \\
\hline & Tema 2 & $\begin{array}{l}\text { - Değişim zorunlu ihtiyaç } \\
\text { • Kökeninden koparak bir değişim } \\
\text { • Farklılıkları yok etmek }\end{array}$ & 3 \\
\hline & Tema 3 & $\begin{array}{l}\text { - Bağımlı hale gelmek } \\
\text { - Dejenere etme potansiyeli yüksek }\end{array}$ & 3 \\
\hline & Tema 4 & $\begin{array}{l}\text { - Gerçek ve sanal dünya ayrımının ortadan kalkması } \\
\text { - Yaşamanın ve var olmanın alameti "görünmek" }\end{array}$ & 4 \\
\hline & Tema 5 & $\begin{array}{l}\text { - Üretmemek } \\
\text { - Tüketmek }\end{array}$ & 6 \\
\hline
\end{tabular}

Amerikan kültürünün sebep olduğu kültür ve/ya kimlik erozyonu kategorisinde 18 kodlama olduğu görülmektedir. Buna göre katılımcılar üretmemek, tüketmek düşüncesinde yoğunlaştıkları görülmektedir. Frekans büyüklüğ̈̈ ise Tema 5, Tema 4, Tema 3=Tema 2 ve Tema 1 şeklinde siralanabilir.

$\mathrm{Bu}$ kategoride öne çıkan görüşlere ilişkin katılımcıların kendi ifadelerinden birkaçı şu şekilde aktarılabilir:

"Amerikan kültürünün ortaya çıkardığı en büyük sorun bir ahlaki ve kültürel boşluk oluşturuyor. Bu da başka kültürler tarafından dolduruluyor. Bu yüzden bizim değişimimiz kaçınılmazdır. Fakat bu değişim kimliğimizden ve kültürümüzden soyutlanarak oluyor... Amerikan kültürünün atmosferi insanı kendine bağımlı hale getirmektedir" (K1)

“Amerikan kültürü baskın olduğu için diğer kültürleri tek bir potada eritiyor. Böylelikle diğer kültürlerin insan ve toplum nezdinde statü ve prestijleri düşüyor." (K3)

"İnsan öyle bir hayatın içine hapsediliyor ki hiçbir duygusal ve psikolojik yetisi kalmıyor. Haliyle bir yalnızlaşma ve yabancılaşma başlıyor." (K4)

"Amerikan kültürünü sebep olduğu en büyük yıkımlardan biri insanları teknolojik aygıtlara bağımlı hale getirmesidir. Bu sayede gerçek ve sanal dünya ayrımı ortadan kalkıyor. İnsanlarda kişilik, rol ve davranış bozuklukları meydana geliyor."(K6)

"Şüphesiz ki Amerikan kültürü bir kriz meydana getiriyor. Hem de ahlaki bir kriz. İnsanlar her şeyi ihtiyaç olarak görüyor. Bu ise inanların temel hedefinin sınırsız bir şekilde tüketmek olduğu anlayışını ortaya çıkarıyor." (K7)

"İşin en ilginç boyutu nedir, biliyor musunuz? Insanların sadece dış görünümünde bir benzerlik/ aynılık yaşanmıyor, aynı zamanda bilinçaltı reflekslerinde de aynı durum söz konusudur. Bu çok korkunç bir şeydir. Bu kültürden olmayanın bir nevi psikolojik yaşam hakkı yoktur. Yani kurulan hegemonya içerisinde bireylerin tüketimleri durmaksızın devam ettiriliyor". (K8) 


\section{Sonuç}

İnsanoğlu ilk zamanlardan beri bir yaşam tarzı çerçevesinde varlığını idame etmiştir. Bu onun yaşamsal ve refleksel formu olmuştur. Bu form gelenekler, adetler, örfler ve toplumun anlayışları diye isimlendirilebilir. İndirgemeci bir yaklaşımla tüm bu form türlerine kültür diyebiliriz. Kültürün etki alanı dilden siluete, yiyecekten giysiye, müzikten mekâna kadar geniş bir spektruma sahiptir. Bundan dolayı kültür, sürekliliğini tüketim ve üretim sirkülâsyonu içinde gerçekleştirmektedir. Haliyle kültürün yaşam sahası toplum olmuştur. Böylelikle ortaya bir tüketim bir de üretim toplumu çıkmıştır. Bauman, mevcut toplumları bir tüketim toplumu olarak değerlendirmekte ve bu toplumun tüketicisi başka zamanda yaşamış tüketicilerden tamamen farklı bir yaratık olduğunu dile getirmektedir. Nasıl atalarımız zamanındaki filozoflar, şairler ve ahlak hocaları insanın yaşamak için mi çalıştığı yoksa çalışmak için mi yaşadığı sorusu üzerine kafa yormuşlarsa, bugünlerde üzerinde en çok kafa yorulduğunu duyduğumuz ikilem, insanın yaşamak için mi tükettiği yoksa tüketebilmek için mi yaşadığı sorusudur (2014, s. 93). Bu sorun aynı zamanda toplumun tüketim algısının, zeitgeistle ${ }^{14}$ ilişkili olduğunu göstermektedir. Çünkü tüketim kültürü, zamanın ruhu-geçerli ahlak haline gelmiştir. Birey bu geçerli ahlakın dinamiklerine göre şekillenmektedir. Dolayısıyla bireyin sosyal ve ahlaki bağlamda değersizleștiği söylenebilir.

Kültür kuramlarıyla ilgilenirken göz önünde bulundurulacak en önemli kavramlardan birisi de küreselleşmedir. Küreselleşme, hem kapitalizmin gelişim sürecinde yeni olmayan bir aşamaya hem de bu aşamayı meşrulaştıracak ideolojik bir olguya işaret eder. İdeolojik olgu işlevini Amerikan popüler kültürü ile yerine getirmektedir. Bu kültür, diğer kültürleri potasında eriterek ve bireyleri de dönüştürerek fonksiyonunu icra etmektedir. Dolayısıyla bir kültürel homojenleşme ortaya çıkmaktadır. Çünkü farklılıklar yok edilmektedir. Bu aynı zamanda tek-tip insan mefhumunu ortaya çıkarmaktadır. Bu anlayışa göre, insanların imaj oluşturma, ikon olma ve kimlik kazanma edinimlerinin en popüler yolu, Amerikan kültüründen geçmektedir. Bu ise toplumda hem kültür hem de tüketim anlaminda bir polarizasyonu meydana getirmektedir. Böylelikle Amerikan kültürünün bir zenginlik olmadığı, aksine kutuplaştırıcı bir özelliğe sahip olduğu söylenebilir. $\mathrm{Bu}$ yönüyle Amerikan yaşam-tarzı çok-kültürlülüğün değil tek-kültürlülüğün bir pratiğidir. $\mathrm{Bu}$ kültürün yeniden üretimi yani merkez noktası tüketime endekslidir. Böylelikle tüketen ama sanal gerçeklik üreten insan modeli ortaya çıkmaktadır.

Amerikanlaşmanın siyasal, sosyal, ekonomik ve kültürel boyutlar başta olmak üzere gündelik hayatın neredeyse her anını ciddi bir şekilde etkilediğini söylemek mümkündür. Bu etki neredeyse her alanda aynı hedeflere ulaşmayı amaçlar: Standardizasyon. Yirmi birinci yüzyılın insanı ve toplumu belirli standartları kendisine hedef olarak seçmiş; siyasi, sosyal, ekonomik ve kültürel anlayışlarını yine bu standartlara göre şekillendirmiş kitlelerden oluşmaktadır.

Amerikan kültürü, yaşamın farklı alanlarına egemen olarak kültürel hegemonyasını kurmuşve dünya çapında kendini evrensel kılmanın başarısını gösterebilmiştir (Çapcıoğlu, 2008, s. 167). Amerikan

14 Zeitgeist kavramı ile kastedilen "her çağın veya dönemin bir ruhu” olduğu kabulüdür. Hegel'de kavram tin olarak anılmaktadır. Detaylı bilgi için bkz. (Hegel, 1995, s. 26, 68-69). 
kültürü, insanlara farklı olma kimliğini aşılayarak üretimini ve sürekliliğini sağlamaktadır. Aslında bu farklı olma iddiası kişinin öz kimliğinden/değerlerinden koparak bir homojenleşme çerçevesinin içine yerleşmektedir. Çünkü bu kültürün en önemli fonksiyonu farklılıkları aynılaştırmasıdır. Bocock’a göre, belli başlı Amerikan dizilerini, milyonlarca insan seyretmekte ve etkilenmektedir. Böylelikle dizilerdeki düşünceler, refleksler, evlerin tasarımı, giysiler, yeme ve içme alışkanlıkları kısaca hepsi bir yaşam tarzı olarak izleyicilerin gözünde arzulanan bir dünya inşa etmektedir (2009, s. 98). Dolayısıyla tüketim kültürü, sadece benzer insanlar meydana getirmekle kalmıyor. Aynı zamanda benzer arzular, düşler ve hazlar da oluşturuyor (Karakaş, 2006, s. 303).

Küreselleşmenin etkileri, Diyarbakır özelinde de hissedilmeye başlamıştır. Küreselleşme, kültürün bir parçası olan insan düşüncesi ve yaşamanı da değişime uğratmıştır. Çünkü $2000^{\prime} 11$ yıllardan önce Diyarbakırlılar, daha çok geleneksel değerlere bağlı oldukları için öncelik bireyin değil, toplumundur anlayışı hâkimdi. Ancak 2000'lı yıllardan sonra toplum parçalanarak birey ortaya çıkmıştır. Haliyle bireyin bu varlığı ve benliği toplumdan soyutlanarak bir kimlik arayışına yönelmiştir. Bu kimlik, etnik kökene ve cinsiyete bağlı olmaksızın tüketim ekseninde tanımlanmaya başlamıştır. Böylelikle gerçek ve sahte ihtiyaçlar ayrımının belirginleștiği bir toplum ortaya çıkmıştır. Bu aynı zamanda gerçek ve sahte hakikatler, kimlikler, yaşantılar vs. meydana getirterek bunları sergilemenin toplumsal bir ayrıcalık ve prestij haline geldiği görülmektedir. Çünkü artık ihtiyaç, bir farklılaşma ihtiyacıdır. Dolayısıyla tüketmek birey için bir zorunluluğa dönüşmektedir. Burada tüketilen sadece maddi mallar ve metalar değil, insanlık ve ona ait değerlerin tümüdür. Artık geçerli ahlak tüketim etkinliğine dönüşmüştür. Bu anlamda tüketim, bireyin özgür bir etkinliği değildir. Çünkü tüketim toplumu, bireyleri nesneleştirerek ve bağımlı hale getirerek, onlara lanse ettiği ve yaşamın amacı haline getirdiği değerlere (bireysel üstünlük, acımasız rekabet, daha çok kazanmak, kazandığını harcamak) sahiptir. Bu değerler ise bireyi özgürleştirmez aksine köle konumuna getirir. Karataş’ın deyimiyle (2006, s. 311) tüketim kültürü, bireylere sunduğu yaşam tarzında sınırsız ve tatmin edilemez ihtiyaçlar sunarak, onları sürekli daha fazlasını istemeye ve arzulamaya yönlendirmektedir. Bu anlayış başlı başına endüstriyel üretim ideolojisinin oluşturduğu ekonomik bir düzendir ve üretimin sürekliliği için tüketimin yeniden üretimini öngörmektedir. Dolayısıyla sınırları belirli olmayan tüketimin, ihtiyaç haline geldiği bir toplumsal yaşama ortamında özgürlükten söz edilemez.

Diyarbakurda Ceylan Karavil Park AVM'deki Starbucks Coffee ile Ninova Park AVM'deki McDonald's'da vakit geçiren insanlar, Amerikan kültür aygitlarını, batı kültürü olarak görmektedirler. Onlar için Amerikan kültürü bir aynılık/benzeşim içerisinde farklılığa işarettir. Kendileri gibi bu kültürü soluyan bireyler ile bir benzeşim mevcuttur. Ancak bu kültürü solumayanlarla ise bir farkll11k söz konusudur.

Zaman içerisinde insanlar, Amerikanlaşma olgusu ile kendi kültürlerinin yok olduğunu fark etmişlerdir. Fakat buna karşı herhangi bir refleks geliştirmediklerini dile getirmişlerdir. Çünkü Amerikanlaşma insan yaşamının bir parçasına değil tümüne nüfuz etmiştir. Amerikanlaşmanın ekonomiden siyasete, eğlenceden sinemaya, yemekten içeceğe her alanda söz sahibi olduğu görülmektedir. Amerikanlaşma bu alanlardaki hâkimiyeti ile kimseye zorla bünyesine 
almamaktadır. Ancak insanlar isteyerek bu alana dâhil olmaktadırlar. Çünkü bu alanın cazibesi ve çekiciliği vardır. İnsanlara imajlar, kişilikler, kimlikler ve farklılıklar sunmaktadır. Böylelikle Amerikanlaşma olgusunun Diyarbakır özelindeki etkisi ve yaygınlığı yumuşak güç olarak değerlendirilebilir. Yumuşak gücün etkisiyle insanların standardize edildiği iddia edilebilir. Örneğin insanların sadece, McDonald's ve Starbucks Coffee'nin servis sistemini ve menüyü beğenmesi ve bu hayat tarzına alışması, onları tek-tipleştirmektedir.

Amerikan kültürünün, sadece Diyarbakırlılar üzerinde değil, dünya üzerinde de bir kültürel hegemonya tesis ettiğinden şüphe yoktur. Bunu ise yumuşak güç diye isimlendirilen kültür aygıtları ile yapmaktadır. İnsanlar, gün geçtikçe kültürel olarak birbirlerine benzemektedir. Kültürel benzeşim sürecinde - araştırma sorularına alınan cevaplarda da görüldüğü gibi - insanların düşünce ve refleksleri de birbirine benzemektedir. Bu Amerikan kültürünün tüketim psikolojisini çok iyi çözümlediğini göstermektedir. Bu psikolojinin temel dinamiğini benlik ve kendilik aparatları oluşturmaktadır. Başka bir ifadeyle insanları tatmin eden ve onlara öncelik sağlayan görünmek, sergilenmek, harcamak ve her şeyi tüketmek gibi aparatlar ile insanlar sosyal medya üzerinden kendilerine rakamsal bir değer biçmektedirler: "Ne kadar like’landım gibi. Çünkü insanların değer yargıları bunlar olmuştur. Onlar için sanal dünya, reel dünyadan öncelikli ve üstündür.

Terazinin bir ucunda Amerikan diğer ucunda ise Diyarbakır halkı yer almaktadır. Amerikan kültürü, ekonomik başarısının verdiği özgüvenle kendini mutlak ve evrensel bir doğru kabul etmekte ve bireylere de bu üstünlüğünü dayatmaktadır.

Ancak genelde Türkiye özelde ise Diyarbakır küreselleşmenin sancılarını toplumsal dinamikler bakımından en kolay tolere edebilecek tarihsel birikime sahiptir. Bu sebeple kendi kültürümüze sahip çıarak, tüketmeyen fakat üreten ve ürettikçe topluma değer katan bir aşamaya ulaşabiliriz. Bunun sağlanması içinse Bayhan’a göre (2011, s. 246) tüketim toplumunun insanı sömürgeleştirmesine, kendisine ve çevresine yabancılaștırmasına karşı yeni bir "etik" üretilmelidir. Bu etiğin temeli dinlerde olduğu gibi, eleştiren ve sorgulayan sosyal bilimlerdedir. Sosyal bilimcilerin daha fazla araştırma yapması ve yayınlaması gerekmektedir. İçinde bulundukları siyasi hegemonyaya yaranmak yerine, gerçekleri ifade eden bir paradigma benimsemesi önem taşımaktadır. Yeni yetişen gençleri bilinçlendirmek için ise; liselerde sosyoloji, felsefe ve psikoloji derslerinin işlevsel ve zorunlu verilmesi şarttır. Özellikle müfredatı yenilenmiş sosyoloji eğitimi yeni etik oluşturmada etkin olacaktır. Sokrates'in "Kendini Bil" mottosu ve Yunus Emrènin "İlim ilim bilmektir/ İlim kendin bilmektir/ Sen kendini bilmez isen / Ya nice okumaktır." Dizeleri hayat felsefemiz olmalıdır. Bununla birlikte yerel kültür, mekân, sanat, okul ve medyamızı değerlerimiz temelinde yeniden inşa etmeliyiz. Küresel kültür karşısında yerel-ulusal ve coğrafyamıza ait olanı, ancak insanımızın bilincini yeniden oluşturarak konumlandırabiliriz. Aksi takdirde küresel kültürün akışına kapılan, tüketim ve görüntüde var olmak dışında bir işlevi olmayan, düşünmeyen, üretmeyen, aslında gerçekte küresel kültürün de bir parçası olamayan ancak yüzeysel taklitle batı kültürünün sadece tüketim ve eğlence, giyinme, müzik gibi taraflarını yaşayan bir toplum dönüşmemiz işten bile değildir. Ve gerçekte bize ait olmayan, bizim dışımızda bize rağmen kendini dayatan bu yeni durumun yaygın hali ile hem Diyarbakır hem de ülkemizde karşılaşmak kaçınılmaz olacaktır. 


\section{Kaynakça}

Althusser, L. (2000). Devletin İdeolojik Aygıtları. İstanbul: İletişim Yayınları.

Arslan, H. (2004). "Küreselleşmenin Emek Üzerindeki İdeolojik Etkileri ve Seçenek Sorunu”. E. A. Tonak içinde, Küreselleşme Emperyalizm Yerelcilik İş̧̧i Sinıfı (s. 163-284). Ankara: İmge Kitabevi Yayınları.

Baudrillard, J. (2012). Tüketim Toplum Söylenceleri/Yapıları. (H. Deliceçaylı, \& F. Keskin, Çev.) İstanbul: Ayrıntı Yayınları.

Bayhan, V. (2011). “Tüketim Toplumunda Bireyin Ontolojik Mottosu: “Tüketiyorum Öyleyse Varım”. Sosyoloji Konferanslart, 221-248.

Berger, P. L. (2003). Küreselleşmenin Kültürel Dinamikleri. P. L. Berger, \& S. P. Huntington içinde, Bir Küre Bin Bir Küreselleşme Çağdaş Dünyada Kültürel Çeşitlilik (A. Ortaç, Çev., s. 9-26). İstanbul: Kitap Yayınevi.

Bocock, R. (2009). Tüketim. (İ. Kutluk, Çev.) Ankara: Dost Kitabevi Yayınları.

Bübül, K. (2009). Kültür ve Medeniyet Tartışmalarına Türkiye’den Bakmak. K. Bülbül içinde, Küreselleşme Temel Metinler (s. 251-263). Ankara: Orion Kitabevi.

Bülbül, K. (2009). Küreselleşme Temel Metinler. K. Bülbül içinde, Küreselleşme Temel Metinler (s. 13-25). Ankara: Orion.

Çapcioğlu, İ. (2008). "Küreselleşme, Kültür ve Din”. AÜİFD (II), 153-183.

Dicken, P. (2009). Yeni-Jeo Ekonomi. K. Bülbül içinde, Küreselleşme Temel Metinler (A. Ağca, Çev., s. 55-63). Ankara: Orion Kitabevi.

Ergün, R. (2016). Selfie: Postmodern Dünyanın Kıblesi. Nida Dergisi (177), 68-69.

Fukuyama, F. (2009). Tarihin Sonu Mu? K. Bülbül içinde, Küreselleşme Temel Metinler (Y. Kaplan, Çev., s. 175-198). Ankara: Orion Kitabevi.

Giddens, A. (2009). Modernitenin Küreselleşmesi. K. Bülbül içinde, Küreselleşme Temel Metinler (K. Bülbül, Çev., s. 161-168). Ankara: Orion Kitabevi.

Gürbilek, N. (2001). Vitrinde Yaşamak 1980’lerin Kültürel İklimi. İstanbul: Metis Yayınları.

Gürbüz, S., \& Şahin, F. (2016). Sosyal Bilimlerde Araştırma Yöntemleri Felsefe-Yöntem-Analiz. Ankara: Seçkin Yayıncılık.

Harvey, D. (2009). Zaman-Mekan Sıkışması ve Post-Modern Durum. K. Bülbül içinde, Küreselleşm Temel Metinler (N. Uslu, Çev., s. 307-328). Ankara: Orion Kitabevi.

Hegel, G. (1995). Tarihte Akıl. (O. Sözer, Çev.) İstanbul: Kabalcı Yayınevi.

Held, D., McGrew, A., Goldblatt, D., \& Perraton, J. (2009). Küresel Dönüşümler, Siyaset, Ekonomi ve Kültür. K. Bülbül içinde, Küreselleşme Temel Metinler (İ. Aktar, Çev., s. 131-154). Ankara: Orion Kitabevi.

Hirst, P., \& Thompson, G. (2009). Küreselleşme - Gerekli Bir Mit Mi? K. Bülbül içinde, Küreselleşme Temel Metinler (N. Uslu, Çev., s. 43-53). Ankara: Orion Kitabevi.

Starbucks. Our Heritage. http://www.starbucks.com.tr/about-us/our-heritage/ erişim tarihi 09.05.2017.

McDonalds. McDonald's History. http://corporate.mcdonalds.com/mcd/our_company/mcdonalds-history. html Erişim tarihi 09.05.2017.

Hunter, J. D., \& Yates, J. (2003). Küreselleşmeye Öncülük Küreselleştirici Amerikan Dünyası. P. L. Berger, \& S. Huntington içinde, Bir Küre Bin Bir Küreselleşme Çağdaş Dünyada Kültürel Çeşitlilik (A. Ortaç, Çev., s. 328-365). İstanbul: Kitap Yayınevi.

Huntington, S. P. (1993). “The Clash of Civilizations?”. Foreign Affairs (72), 22-49.

İçli, G. (Aralık 2001). Küreselleşme ve Kültür. C.Ü. Sosyal Bilimler Dergisi, 25 (2), 163-172.

Kahraman, H. B. (Pazar Haziran 2011). “Çağdaş Hapishaneler: AVM’ler”. Sabah, sayfa yok. 
Kalb, D., \& Land, M. V. (2009). Mozayiğin Ötesi: Küreselleşen Bir Çağda Kültürel Kimliğin Sorgulanması. K. Bülbül içinde, Küreselleşme Temel Metinler (Z. Tüysüz, Çev., s. 271-278). Ankara: Orion Kitabevi.

Lieber, J. R., \& Weisberg, E. R. (2009). Küreselleşme, Kültür ve Kimlik Krizi. K. Bülbül içinde, Küreselleşme Temel Metinler (K. Bülbül, Çev., s. 347-370). Ankara: Orion Kitabevi.

Mazrui, A. A. (2009). Evrensellik İddiası: Küreselleşen Bir Çağda Batı Kültürü. K. Bülbül içinde, Küreselleşme Temel Metinler (H. Arıkan, Çev., s. 415-432). Ankara: Orion Kitabevi.

Modelski, G. (2009). Küreselleşme. K. Bülbül içinde, Küreselleşme Temel Metinler (K. Bülbül, \& R. Yaslıkaya, Çev., s. 155-160). Ankara: Orion Kitabevi.

Murray, R. (1995). Fordizm ve Post-Fordizm. S. Hall, \& M. Jacques içinde, Yeni Zamanlar 1990’larda Politikanın Değişen Çehresi (A. Yılmaz, Çev., s. 46-62). İstanbul: Ayrıntı Yayınları.

Perraton, J., Goldblatt, D., Held, D., \& McGrew, A. (2009). Küreselleşen Bir Dünyada Ekonomik Aktivite. K. Bülbül içinde, Küreselleşme Temel Metinler (N. Demirci, Çev., s. 27-41). Ankara: Orion Kitabevi.

Postman, N. (2016). Televizyon: Öldüren Eğlence Gösteri Çağında Kamusal Söylem. (O. Akınhay, Çev.) İstanbul: Ayrıntı Yayınları.

Ritzer, G. (2008). Modern Sosyoloji Kuramları. (H. Hülür, Çev.) Ankara: De Ki Basım Yayım LTD.

Ritzer, G. (2009). McDonaldlaştırmaya Giriş. K. Bülbül içinde, Küreselleşme Temel Metinler (Ş. S. Kaya, Çev., s. 371-390). Ankara: Orion Kitabevi.

Robson, C. (2015). Bilimsel Araştırma Yöntemleri Gerçek Dünya Araştırması. Ankara: Anı Yayıncılık.

Roscoe, P. (2015). Harcıyorum Öyleyse Varım Ekonominin Gerçek Maliyeti. (A. Çavdar, Çev.) İstanbul: Ayrıntı Yayınları.

Smith, A. D. (2009). Global Kültüre Doğru. K. Bülbül içinde, Küreselleşme Temel Metinler (Z. Tüysüz, Çev., s. 297-306). Ankara: Orion Kitabevi.

Şaylan, G. (2003). Değişim, Küreselleşme ve Devletin Yeni İşlevi. Ankara: İmge Kitabevi.

Şaylan, G. (2008). Temsili Liberal Demokrasinin Önlenemez Krizi. Ankara: İmge Kitabevi Yayınları.

Şeriati, A. (2013). İnsanın Dört Zindanı. (H. Hatemi, Çev.) Ankara: İşaret Yayınları.

Tomlinson, J. (2014). Küreselleşme ve Kültürel Kimlik. D. Held, \& A. McGrew içinde, Küresel Dönüşümler Büyük Küreselleşme Tartışması (B. Özçelik, Çev., s. 320-329). Ankara: Phoenix Yayınevi.

Yıldız, N. (2012). “Yeni Zamanlar” ve Yeni Liderlik Anlayışı. Ankara Avrupa Çalışmaları Dergisi, 11 (1), 119134. 
